\title{
A Study on the Concept-Driving Oral English Teaching and Its Effectiveness on Speech Production in EFL Context
}

\author{
Shiyong Jiang \\ School of Foreign Languages, Leshan Normal University, 778\#, Binhe Road, Shizhong District \\ Leshan, Sichuan Province, 614000, P. R. China
}

jsyenglish@126.com

\begin{abstract}
Keywords: Concept formation; Thinking; Oral English teaching; Speech production
\end{abstract}
\begin{abstract}
Formation of concepts in learning a foreign language is one of the key reflections of mastering the language. With such illumination, an experiment of concept-driving model of oral English teaching was carried out. It is justified that there is strong correlation between concept formation and speech production. EFL teachers ought to emphasize the development of students' English thinking, combine the classroom teaching and after-class practice systematically so as to promote students' speech competence effectively.
\end{abstract}

\section{Introduction}

Being able to convey ideas into overt speech in L2 or FL has always been the learning objective of most L2/FL learners around the world. However, this has always been a problem for many foreign language learners, especially for EFL learners in China since for a long time, foreign language ability was the synonym of ability to deal with examination. In the practice, we find many students can not speak fluently with well-structured sentences and precise words. How to cultivate students' fluent and complex oral production? There have been endless disputes or argumentations ever since last century.[1][2] According to the studies of cognitive linguistics, thinking is the "inner language" of the speaker, while inner language is in fact the manifestation of concepts in the mind, that is, the reflection and manipulation of the representation of the physical world. Therefore, learning a new language is in fact forming the new concepts in the mind, or in other words, to be able to think in the language.

In fact, thinking in a foreign language has once been a hot topic and been paid much attention to in the study of applied linguistics for long in the world. Many researches noted that it was just because of the lack of the core of thinking in the target language (TL) that learners have difficulty in understanding and speaking the TL.[3] Scholars believe that the cultivation of students' oral ability must consider the development of the thinking in the TL. As Doctor Nida once noted, thinking in a foreign language is absolutely necessary for the learners. If the learner always translates English into his or her mother tongue, it is impossible to express himself or herself fluently and delicately. [4] Based on such understanding, this paper, regarding the development of foreign language concepts as the core, probes into the effectiveness of concepts-driving teaching model of oral English both theoretically and experimentally in an EFL context, with the hope to throw some light on oral English teaching and the improvement of the quality of oral English production.

\section{Research Background}

Children's conceptual system is interrelated with the development of their mother tongue simultaneously or even before they acquire the language.[5] From such a perspective, if the core of concept formation can be ensured, acquisition of the language can be ensured. Oral production is in fact a process in which inner language or thought of the speaker has been externalized or turned into the real language phonetically, syntactically and textually. This, in fact, is a process through which the thought becomes externalized verbally, that is, a process when the words and sentences are organized effectively to express the concepts at various levels in the mind. With such an 
understanding, one of the important reasons why the traditional teaching model is severely restricted is that the development conceptual system has been overlooked. In reality, people use certain language while they are thinking, including retrieving mental lexicon, choosing syntactic structure and noticing the logic meaning and so on.

However, since the conceptual system is the common core of language and thinking, it is very difficult to set another conceptual system and thinking in another language must be a long-term and difficult process once the mind acquired L1.[6] Hard as it is, it is still possible to grasp the core of language acquisition and create the required "environment" since the nature of it is to engage speakers in thinking and speaking by using the language in question, namely, we can engage learners in certain thinking and speaking practice with L2/FL as the tool. Through large amount of practice, it is useful to make learners be more familiar with the process of retrieving words and organizing sentences to express ideas so as to make an "approximate" foreign language conceptual system.[7] In so doing, the TL and its conceptual system can be formed gradually, ensuring the fluent oral language ability.

\section{The Research}

The Main Assumptions and Research Questions. The present study, based on years of experiences of teaching college EFL in Chinese context, proposed a model of oral English teaching based on the development of students' conceptual system in the TL, that is, English will be used as a thinking tool purposefully in cognition and communication so as to realize the real value of a language. The main assumption of is: through certain well designed activities which require students to think and speak in English, especially in an E-learning environment, it is helpful to promote students to form the English conceptual system from being simple to complex. The main research questions of this study include: 1) Is the concept-driving teaching model more effective than the traditional one? 2) Is there any statistically apparent change in the learning outcome of this model? If there is, then how does the conceptual system influence students' oral English performance?

Research Subjects. Subjects of this study are 28 sophomore undergraduate students who majored in English (EFL) from a university in west China. Their ages range from 20 to 22. To have the comparative effect, another parallel class of 29 students was chosen. The time of teaching experiment is one term in Grade two in university. The reason why they are chosen for this experiment is that after one year of learning, they have developed more words and their oral English have been developed apparently. Therefore, they can engage in basic thinking and oral communication in English. What's more, they are highly motivated to participate in oral activities to pass the oral test of TEM4 (Test for English majors in China).

The Experiment and Research process. Before the experiment, on the one hand, we mobilized students to fully participate in the learning program, grasp any chance to practice and form the "thinking habit" which may lead to better oral English proficiency; on the other, detailed rules and suggestions are made for students to follow in after-class oral activities. The thinking activities are divided into two types: one is for the input activity and another is for the output activity. The output activity is the core and the input serves the base of output. During one term of experiment, the in-class and outside-class activities are integrated systematically. Outside the classroom, students are divided into different groups to practice thinking and speaking in English using all the possible means, such as WeChat, QQ, or face to face communication. The group members will do the same activities set by the whole group with the guidance of the teacher. The purpose is to organize students in inner language rehearsal (the concept formation practice) and oral English practice. Then, the oral English class will focus on the consolidation, extension of thinking in English and check the effectiveness of after-class learning in which students will have different types of oral production to promote the transition from inner speech to the real verbal production. After one term, students of the experimental and another parallel class will take the same final examination for the contrastive result.

Data in the Final Examination. Three criteria of oral English are adopted in the assessment of 
oral achievement, namely, fluency, accuracy and complexity. The 28 subjects in the experimental class are divided into 4 groups. For contrast, in another parallel (controlled) class, 29 students are divided into 4 groups. In order to prevent subjective impression of the assessor who teaches the class, another native speaker (teacher) was invited to evaluate the students. The content of the test includes three parts. Part A is prepared presentation with the topics given 10 minutes before the test, of which, the weight is 0.4 . Part B is interactive conversation with the weight of 0.3 , in which one examiner will talk with the student; Part $\mathrm{C}$ is unprepared questions with the weight of 0.3 . Students are required to choose 3 out of 15 questions.

The complexity of sentences is investigated because the externalization of thinking is mainly in the production of sentences, that is, the real concepts and thought can be carried by the language. Therefore, T-unit of sentences in oral language is chosen as the crucial criterion. It incorporates the structure of clauses, subordinate clause and some other independent units not in the form of a complete sentence. At the same time, in order to understand how teaching influences the complexity of oral English, the complexity of vocabulary is also investigated. Specifically, the rate of word forms and words is studied. This study chose 10 students from the two classes randomly as research subject. their speech in Part A is transcribed into written form to investigate the effective word forms, $\mathrm{T}$ units, clause and subordinate clause. The data from these studies are input in computer for statistics by SPSS 17.0.

\section{Data Analysis and Discussion}

The Contrast of the Achievements of the two Classes Before the Experiment. Before the experiment, students of the two classes were evaluated for their initial proficiency of oral English. Their scores of last term were used for evaluation. the independent $\mathrm{T}$ test is adopted for the contrast of the scores. The result is $\mathrm{T}=0.955, p(2$-tailed $)=0.324$, higher than 0.05 as we set in the test at the beginning. Therefore, it is safe to say that the two classes do not have apparent differences before the experiment. After the experiment, a Chinese teacher and a native speaker teacher evaluate the achievements together. The average point will be the final score of the student in evaluation. Independent $T$ test shows that there is no significant difference between the evaluation by the Chinese and the native teacher with the scores from the native speakers a little higher. With the average division, there is no influence on the effectiveness of the evaluation. The Normal distribution exploration test indicates that the variances of the two classes are equal. The Skewness of the experimental class is -.64 and $\mathrm{M}$ estimator is between 82.86 to 82.89 , which is in accordance with the requirement of Normal Distribution. As for the controlled class, the Skewness is .395 and $\mathrm{M}$ estimator is between 78.77 and 78.91 , which is in accordance with the requirement of Normal distribution. Then an Independent $T$ test is carried out. The following table shows the result:

Table 1 The independent T-test of the scores of two classes

\begin{tabular}{lcccccccc}
\hline $\begin{array}{l}\text { Levene's Test fort } \\
\text { Equality of Variances }\end{array}$ & \multicolumn{1}{l}{ Independent T-test for Equality of Means } \\
\hline & $\mathrm{F}$ & $p$ & $\mathrm{~T}$ & $\mathrm{df}$ & $p(2$-tailed) & \multicolumn{2}{l}{$\begin{array}{l}\text { 95\% Confi. } \\
\text { Lower }\end{array}$} \\
& & & & & & & Upper \\
Equal & 1.247 & .269 & 2.668 & 54 & .008 & .965 & 6.035 \\
Not Equal & & & 2.668 & 52.75 & .008 & .964 & 6.036 \\
\hline
\end{tabular}

Table 2 The paired T-test of the experimental class before and after the experiment

\begin{tabular}{|c|c|c|c|c|c|c|}
\hline \multicolumn{7}{|c|}{ The Paired T-test of the two classes } \\
\hline & & & & $\mathrm{T}$ & $\mathrm{df}$ & $p$ (2-tailed) \\
\hline \multirow[t]{2}{*}{ Mean } & S.D. & $95 \% \mathrm{C}$ & & & & \\
\hline & & Lower & Upper & & & \\
\hline-6.107 & 3.499 & -7.464 & -4.750 & -9.234 & 27 & .000 \\
\hline
\end{tabular}


The average difference between two classes is 3.5. Is this variance the in-group variance or between-group variance? Table 1 provides the answer $(\mathrm{T}=2.668, p(2$-tailed $)=0.008)$. It shows that the significance is lower than the set value (.05). That is to say, there is noticeable variance between the two classes which is caused by the experiment or the so called between-group difference, not the within-group factors. Apparently, compared with the tradition model of EFL teaching as in the controlled class, oral English teaching with the thinking-driving model is more effective. In the mean time, it is also found that after one term of teaching and learning, the standard deviation in the two classes are both broadened than before, and the value of it in the experimental class is lower than the controlled class. Probably this is related to the efforts of the students, the deviation of the motivation and how they participate in after-class activities.

Table 2 is the Paired T-test of the scores of experimental class before and after the experiment. The finding $(\mathrm{T}=-9.213, p$ (2-tailed)=.000) indicates that there is significant difference between the scores of the two times, showing that students' achievement is apparently improved compared with that before the experiment. Therefore, considering the result of the experimental class and controlled class and the changes after the teaching experiment, it is now confident to believe that this thinking-based model is better than the traditional one in teaching English as a foreign language for Chinese English major students. Learning English with thinking competence as the core is effective than just learning grammar and memorizing words and texts merely.

The Influence of the Teaching Model on the Complexity of Oral Production. After the experiment, 10 students were chosen from the two classes as the research subjects. Part A of the final exam was used as the target for investigation. In fact, though thinking is very crucial for concept formation, it is implicit and difficult to measure. As a result, this study mainly focuses on the time that students spent on thinking and speaking activities, the complexity of words, the length of T-unit, the length of the independent clause, the rate of subordinate clause. The Scatter plot diagram shows that there is possible rising linear relation which may indicate the positive correlation. As the sample is small, Spearman non-parametric test was adopted for analysis. With regard to the complexity, Man-Whitney non-parametric test was chosen. The findings are in the following tables:

Table 3 The correlation test between thinking and speech complexity

\begin{tabular}{lccccl}
\hline & & $\begin{array}{c}\text { complexity } \\
\text { of T-unit }\end{array}$ & $\begin{array}{l}\text { length of } \\
\text { T-unit }\end{array}$ & $\begin{array}{l}\text { length of } \\
\text { subordinate } \\
\text { clause }\end{array}$ & $\begin{array}{l}\text { rate of } \\
\text { subordinate } \\
\text { clause }\end{array}$ \\
\hline Time & $\mathrm{R}$ & .636 & .685 & .564 & -.006 \\
Spent & $p(1$-tailed $)$ & .024 & .014 & .045 & .493 \\
& $\mathrm{~N}$ & 10 & 10 & 10 & 10 \\
\hline
\end{tabular}

Table 4 The non-parametric test of the speech complexity of the two classes

\begin{tabular}{lllll}
\hline & $\begin{array}{l}\text { complexity } \\
\text { of words }\end{array}$ & $\begin{array}{l}\text { length of } \\
\text { T-unit }\end{array}$ & $\begin{array}{l}\text { length of } \\
\text { clause }\end{array}$ & $\begin{array}{l}\text { rate of } \\
\text { subordinate } \\
\text { clause }\end{array}$ \\
\hline Mann-Whitney $\mathrm{U}$ & 48.50 & 23.00 & 27.00 & 36.00 \\
$\mathrm{Z}$ value & -.114 & -2.041 & -1.739 & -1.063 \\
$p$ (1-tailed) & .912 & .043 & .047 & .315 \\
\hline & & & & $(\mathrm{p}<.05)$
\end{tabular}

The Mean of the length of T-unit is 12.06 and the Mean of clause length is 8.56 , indicating a better development tendency. As the probability condition $p$ is lower than the set value .05 , the linear correlation among the time of thinking in TL, the length of T unit, the length of clause is apparent. Spearman Correlation Coefficient $R$ reaches to $0.636,0.685$ and 0.564 , showing a direct correlation among the several factors. It is easy to find that with the implementation of the new model of oral English development, word complexity, the length of T-unit and clauses are all improved. The changes of word complexity and the length of T-unit are significant with the $p$ value 
of .024 and .014 . Meanwhile, the $p$ value of the clause length is .045 which also satisfies the basic requirement of being significant. However, the influence of thinking in the foreign language on the rate of subordinate clause is not statistically significant $(p=.493)$. This result is basically in line with Bardovi-Harlig and Bofman in their research. [8]

Although the experimental class outperformed the controlled class in the four indexes aforementioned, it is still necessary to check it statistically. Seeing from Table 4, the result is not significant $(\mathrm{Z}=-1.14, p=.912)$, showing that the word stock in the two classes are developing and the engagement of thinking in English can hardly make some significant differences. The changes in the length of $\mathrm{T}$ unit is significant statistically $(\mathrm{Z}=-2.041, p=.043)$. The significance of the length of clause is .043 , close to the critical point $(p=0.05)$. Through the above analysis of the data, it can be found that foreign language concept formation or thinking is beneficial for students to broaden the ideational unit or T unit as some scholars mentioned. Such a model of teaching would help students to be more familiar with the process of expressing ideas by retrieving words and sentence from the mind. However, this model still make little or on difference on the length of clause and the rate of subordinate clauses. Probably this is because students develop slowly at such a stage of acquisition as a general tendency and the function of thinking in the target language mainly benefits improving the holistic ideational unit, not the single clause.

\section{Major Findings of This Study}

Concept-driving Teaching Model is more Effective than the Traditional Ones. As found in this study, the formation of the foreign conceptual system is helpful for students to make effective expression. In EFL context, students still can construct their foreign language concept to some extent. In colleges, if oral English teachers can emphasize the core of concept in English, the teaching for sure will be more effective. To develop students' foreign language thinking, there must be reform in oral English teaching. The teacher must utilize the relation between the thinking and language, combine the in-class and outside-class activities together and encourage students to engage in thinking in English to form their own English conceptual system.

The Complexity of Oral English can be Improved in a Concept-Driven Oral English Class. Complexity is always an index to measure the quality of speech in a foreign language. And, as what have been found in this experiment, foreign language thinking indeed helps to improve the complexity of students' oral English. It is useful to cultivate the ability of students to think and speak in a foreign language since it can lengthen the ideational units. As the finding indicates, the length of students' sentence, the choice of words will all be bettered after this teaching model. Therefore, oral English teaching should focus on how to provide students more chances to think and speak in the TL so that they can become more familiar with the organization of words, phases and the related structures to express richer concepts.

Mother Tongue Thinking has Strong Influence on Oral Production. This study also finds that although we have various training and activities of thinking and speaking in the target language, some indexes of language complexity, such as the rate of embedded or subordinate clauses do not improve apparently as expected. Dose this mean the deficiency of students' oral English? Is this caused by the rule of learning a foreign language for Chinese learners? One possible answer may be that oral communication requires brevity and clearness and it's difficult for students to construct a sentence with complex structures in the limited time. As reported by many students, when facing some complex situation, they tend to rely on Chinese as the cognitive and thinking tool. Teachers need to find ways to promote students to think in English.

\section{Conclusion}

Learning a language is forming the conceptual system of this language. The formation of the conceptual system of a language is the essence of using the language as argued by many researchers. This study probes into concept-driving model of oral English. It is found that this model is effective in enhancing oral English proficiency in its fluency, accuracy and complexity. Therefore, it's 
essential that both the EFL teacher and students have the awareness of forming the conceptual system of the TL. In particular, the teacher need have a good understanding thinking in English for conceptual formation and teaching the language accordingly. To develop student's oral English, considering the practical situation of EFL learning, it's necessary to create a context of using English, namely, thinking and using the language both in and after class. In doing so, an effective mechanism of learning and teaching must be built flexibly. Oral English proficiency does not depend completely on classroom teaching, more time and energy must be ensured after the class and in the life. This study is preliminary which only investigated the relationship between the time students spent and their oral achievements. To what degree is the time spent for thinking in the target language related to language production is still problematic. Besides, more studies are required to explore the specific complex relationship among accuracy, complexity and fluency with bigger samples in the future.

\section{Acknowledgements}

This paper is supported by Scientific Research Found of Sichuan Provincial Education Department. (grant number: 17SB0168)

\section{References}

[1] W, Z, Zhang and X., D., Wu The quantitative study of the Oral fluency of second language, Modern Foreign Languages , 2001, (4): 341-351.

[2] Z, Liu. Exploring the influential factors on L2 Learners' Oral Production, Foreign Languages and Their Teaching, 2009, (7): 26-28.

[3] A, Waters, Thinking and Language Learning, ELT Journal, 2006, (4): 319-327.

[4] E, Nida, Learning a foreign language: A handbook prepared especially for missionaries, New York: Friendship Press, 1957.

[5] J, Piget, Children's Language and Thinking, Beijing: Culture and Education Publishing House, 1980.

[6] N, Jiang, The Formation of Foreign Language Concept and Foreign Language Thinking, Modern Foreign Languages, 2004, (4): 378-385.

[7] M, C, Guerrero, Inner Speech-Thinking Words in A Second Language, New York: Springer, 2005.

[8] K, Bardovi-Harlig and T, Bofman, Attainment of syntactic and morphological accuracy by advanced language learners, Studies in Second Languages, 1989, (11): 17-34. 